\section{Please Doctor, Resist NOTES!}

\section{To the Editor:}

$\mathrm{n}$ the August issue of Annals of Surgery, Lehmann et al reported on the German experience with 551 Natural Orifice Translumenal Endoscopic Surgery (NOTES) procedures. ${ }^{1}$ NOTES has been proposed as a new surgical innovation allowing surgical procedures via natural orifices to achieve improved surgical cosmetic results. For abdominal surgery, these potential orifices are the vagina, the mouth (through a gastrotomy), or the anus (through a rectotomy or a colostomy). The article by Lehmann et al is a report on the voluntary registry of procedures, mainly cholecystectomies, performed on women using a hybrid, rather than pure NOTES technique. Most cases presented in the report involved $10 \mathrm{~mm}$ transvaginal access and $5 \mathrm{~mm}$ umbilical trocar, with a follow-up period of 1 month. ${ }^{1}$ Mean hospital stay for these cholecystectomies was 3.2 days. The authors reported a few intra- and postoperative complications, most of which were minor and related to the vaginal access. In our opinion, this report raises several significant issues.

First, caution has to be taken when we, surgeons, evaluate complications occurring in our own practice on a purely voluntary retrospective basis. We have a natural tendency to neglect or forget some of the complications encountered. To illustrate this, it is very intriguing that this report of 488 hybrid NOTES cholecystectomies does not describe any bile duct injury, a complication that is known to be significantly more common in "classical" laparoscopic cholecystectomies than in open cholecystectomies. ${ }^{2}$ There is no reason for hybrid NOTES techniques to be safer than the standard practice, especially if bile duct opacification is not performed. ${ }^{3}$ The complications of a new procedure such as NOTES must be evaluated prospectively if a study is to be meaningful.

In addition, I do not agree with the authors' argument that an ethical review is not necessary when proposing a NOTES technique for cholecystectomy and for publishing the results of this procedure. As the report by Lehmann et al demonstrated, this new surgical technique has specific complications that have yet to be evaluated carefully.
Ethical review and patient informed consent are likely to protect not only the patients, but also the surgeons proposing these techniques. In addition, toward the end of their article, the authors mentioned that transrectal NOTES procedures have been performed on male patients upon completion of their analysis. Personally, I do not want my gallbladder removed through my colon, and I do not want to be the surgeon who will have to perform the first diverting colostomy following complicated transrectal or transcolonic NOTES, as this is bound to happen; besides the medical harm inflicted on the patient, there is no way to defend such a complication following transrectal cholecystectomy in a lawsuit.

The main question raised by the Lehmann report is the future role of (hybrid) NOTES techniques in cholecystectomies and other abdominal procedures. One of the arguments of NOTES proponents is that these techniques will be the next innovative step in surgery, just as laparoscopy revolutionized abdominal surgery 20 years ago. The advantages of laparoscopy on open surgical techniques are obvious, with less trauma and pain for the patient. Cosmetic advantages are also clear, but should be considered a less significant consequence. Laparoscopy allowed for the introduction of minimal invasiveness and fast-tracking. ${ }^{4}$ These advantages are far greater than the particular complications of laparoscopic techniques, such as an increased incidence of bile duct lesions for laparoscopic cholecystectomies. As a result, laparoscopy is now the standard approach for numerous abdominal procedures. What are the potential advantages of hybrid NOTES techniques, other than cosmetic, on laparoscopy? A hybrid NOTES approach, as described by Lehmann et al, requires a $\mathrm{CO}_{2}$ pneumoperitoneum and a $5 \mathrm{~mm}$ trocar in the umbilicus. In Lehmann's series, mean hospitalization time was 3 days. Complications were linked to the vaginal trocar, in addition to the instrumental costs, which are somewhat higher than those of laparoscopy. As a physician and surgeon, I find the possibility of a transgastric or transcolonic approach for cholecystectomy to be even more intriguing. The necessity of a total colonic cleaning and decontamination to perform a cholecystectomy seems senseless to people who experienced bowel preparation for a colonoscopy, as I did. ${ }^{5}$ I do not wish to elaborate further on the issue of the cost of the bowel closing devices, and the occurrence of tragic complications following such procedures.

Is hybrid NOTES the future of cholecystectomy? As you may have noted, I doubt it, but this technique at least needs to be carefully assessed by large, controlled, and randomized studies. Laparoscopic cholecystectomy can be safely performed with $2 \mathrm{~mm}$ trocars in addition to the umbilical trocar, with minimal scarring and very short hospital stays $(<12$ hours). Despite this, most surgeons are still using two $5 \mathrm{~mm}$ and one or two $10 \mathrm{~mm}$ trocars, and hospitalizations of 1 or 2 days. This demonstrates that, in clinical practice, surgical comfort and patient safety are superior to pure esthetic considerations. The single-incision laparoscopic surgery (SILS) may be considered a more attractive approach for the time being, but its role still needs to be assessed by careful medical and costeffectiveness evaluation. ${ }^{6}$ Although awaiting the outcome of these evaluations, the surgical community must resist the increasing pressure from the surgical industry, as well as the natural surgeons' fear that they will "miss the boat" of NOTES.

Olivier Detry, MD, PhD Department of Abdominal Surgery and Transplantation

University of Liège, CHU de Liège Wallonia, Belgium oli.detry@chu.ulg.ac.be

\section{REFERENCES}

1. Lehmann KS, Ritz JP, Wibmer A, et al. The german registry for natural orifice translumenal endoscopic surgery: report of the first 551 patients. Ann Surg. 2010;252:263-270

2. Connor S, Garden OJ. Bile duct injury in the era of laparoscopic cholecystectomy. Br J Surg. 2006;93:158-168

3. Detry O, De Roover A, Detroz B, et al. The role of intraoperative cholangiography in detecting and preventing bile duct injury during laparoscopic cholecystectomy. Acta Chir Belg. 2003;103:161162.

4. Kehlet H, Wilmore DW. Evidence-based surgical care and the evolution of fast-track surgery. Ann Surg. 2008;248:189-198.

5. Detry O, Nsadi B, Kohnen L. Natural orifice transluminal endoscopic surgery (NOTES): when a step forward may be a step too soon or too far. Surg Endosc. 2010;24:1213-1214.

6. Edwards C, Bradshaw A, Ahearne P, et al. Singleincision laparoscopic cholecystectomy is feasible: initial experience with 80 cases. Surg Endosc. 2010;24:2241-2247.

\footnotetext{
Disclosure: The author declares that there is nothing to disclose.

Copyright (C) 2011 by Lippincott Williams \& Wilkins

ISSN: 0003-4932/11/25405-0001

DOI: $10.1097 /$ SLA.0b013e318235f3e 5
} 